\title{
Models of open populations with space-limited recruitment in stochastic environments: relative importance of recruitment and survival in populations of Semibalanus balanoides
}

\author{
Carl J. Svensson ${ }^{1, *}$, Stuart R. Jenkins ${ }^{2}$, Stephen J. Hawkins ${ }^{2}$, Alan A. Myers ${ }^{5}$, \\ Pedro Range ${ }^{3}$, José Paula ${ }^{3}$, Ruth M. O'Riordan ${ }^{4,5}$, Per Åberg ${ }^{1}$ \\ ${ }^{1}$ Department of Marine Ecology, Göteborg University, Box 461, 40530 Göteborg, Sweden \\ ${ }^{2}$ Marine Biological Association, Citadel Hill, Plymouth PL1 2PB, UK \\ ${ }^{3}$ Institudo do Mar (IMAR), Laboratório Marítimo da Guia, Faculdade de Ciências da Universidade de Lisboa, \\ Estrada do Guincho, 2750-642 Cascais, Portugal \\ ${ }^{4}$ Department of Biological Sciences, National University of Singapore, 14 Science Drive 4, Singapore 117543 \\ ${ }^{5}$ Department of Zoology and Animal Ecology, National University of Ireland, Lee Maltings, Prospect Row, Cork, Ireland
}

\begin{abstract}
The relative importance of recruitment and post-recruitment processes in determining adult density among marine species varies considerably between species and populations. This study aimed to investigate the relative effects of variation in recruitment and survival rates on the density dynamics of 3 spatially separated natural populations of the barnacle Semibalanus balanoides (Isle of Man, SW Ireland and west Sweden). We analysed 2 different data-based stochastic matrix models of open populations with space-limited recruitment. Assumption testing supported the application of matrix-model theory for studying and comparing population variables of open populations. Recruitment was found to be partly dependent on free space, and mortality was size-specific and independent of other vital rates. Model simulations showed that the relative importance of recruitment and survival in shaping adult density depends on the existing variation of these vital rates at each location. In the Isle of Man the variation in density was primarily caused by variability in recruitment, while in SW Ireland the variability in survival induced the most variation. In west Sweden variation was high due to variability in both recruitment and survival. A life-cycle elasticity analysis across locations indicated that the population dynamics were generally more sensitive to changes in survival than to changes in recruitment. Also, locations with high variability in vital rates seemed better able to buffer sudden changes in vital rates. In addition, differences in survival and growth produced population structures that varied between populations. In the Isle of Man and west Sweden the populations consisted of mainly Size Category 1 individuals, while the population in SW Ireland had a linear relationship between size category and the proportion of individuals.
\end{abstract}

KEY WORDS: Intertidal rocky shore $\cdot$ Matrix model $\cdot$ Stochastic vital rates $\cdot$ Free space $\cdot$ Northern Europe Resale or republication not permitted without written consent of the publisher

\section{INTRODUCTION}

The relative importance of recruitment and postrecruitment processes in determining adult density among marine species is a contested issue (Grosberg \&
Levitan 1992, Caley et al. 1996, Hughes et al. 2000). Some studies have suggested that recruitment (and settlement) can be the main determinant of adult density (Doherty 1981, Gaines \& Roughgarden 1985) while others have shown that post-recruitment pro- 
cesses are equally or more important (Connell 1985, Caley et al. 1996, Menge 2000, Fraschetti et al. 2002). Most likely the relative impact of different life-cycle stages on the population dynamics of species or species assemblages varies considerably between species and populations. Consequently, detailed demographic monitoring of recruitment and mortality at several spatial scales is needed when evaluating which life-cycle stages shape observed density patterns for a particular species.

Marine benthic invertebrates display a range of different life histories, but a large proportion have separate larval planktonic and adult benthic stages (Thorson 1950, Caley et al. 1996). For those species with pelagic larvae, migration among spatially separated populations may be high, and hence local recruitment is independent of local larval production (Nisbet \& Gurney 1982, Gaines \& Roughgarden 1985, Hyder et al. 2001). Local recruitment is however often partly space-dependent and declines with density of adults (Roughgarden et al. 1985). In a stable environment, where an organism has little variation in local vital rates, this would usually produce a state of equilibrium in which recruitment, growth and mortality are in balance. On the other hand, few if any environments are stable, and differences in microhabitat and other local factors produce high variation in small-scale vital rates of most populations (Roughgarden et al. 1985, Caswell 2000).

Intertidal barnacles are suitable organisms for demographic studies. They are abundant in the intertidal zone of rocky shores and easily accessible for field studies. In addition, barnacles are important competitors for space and have a dominant role in the dynamics of the mid-intertidal zone (Hartnoll \& Hawkins 1985, Young \& Gotelli 1988, Jenkins et al. 2001). Barnacles also have pelagic larvae with a relatively long planktonic stage and occur as open populations with high rates of dispersal. Consequently, local settlement and recruitment rates and post-recruitment survival are partly decided by large-scale factors, such as off-shore hydrodynamic processes (Barnes 1956, Raimondi 1990, Bertness et al. 1991) and the reproductive output of adjacent populations (Hawkins \& Hartnoll 1982, Raimondi 1990, Minchinton \& Scheibling 1991), and partly by smallscale factors such as surface contour (Crisp \& Barnes 1954), habitat and biofilm quality (Pineda \& Caswell 1997, Wieczorek \& Todd 1998, Olivier et al. 2000, Holmes 2002), individual larval behaviour (KnightJones 1953, Hills et al. 1998, Jeffery 2000), biological interactions (Dayton 1971, Hawkins 1983, Hartnoll \& Hawkins 1985) and the amount of available space (Roughgarden et al. 1985). This complex interaction of factors, acting at different spatial scales, produces large fluctuations in local population dynamics.
Matrix models are useful tools for investigating the demography of many plants and animals (Caswell 2000), enabling the linking of mechanisms acting at the individual level through to population level processes. Population matrix models are therefore frequently applied in different types of demographic studies (see Tuljapurkar \& Caswell 1997 and Caswell 2000 for reviews). In this study, the populations can be considered open, and vital rates for these populations are likely to experience a great deal of variation (Cohen 1987, Tuljapurkar 1990, Hanski 1996, Caswell 2000). Therefore, to adequately link individual vital rates to demography in these models, we believe that the use of stochastic processes, such as variability in recruitment and survival, rather than a purely deterministic approach would produce the most realistic measures of population dynamics (Tuljapurkar 1990, 1997, Levin 1992).

Significant small- and large-scale differences in recruitment and mortality for the barnacle Semibalanus balanoides have been found between and within several locations in northern Europe (Jenkins et al. 2000, 2001). However, no attempt has been made to estimate, through modelling, the relative effects of this variation in recruitment and survival on the density dynamics of these populations. The aim of this work was to examine and quantitatively compare the effects of small-scale variation in vital rates on the variation of population growth rate, density, free space and structure for 3 spatially separated populations of the barnacle $S$. balanoides (L.). Thus, the main objective was to estimate the individual and combined effects of recruitment and post-recruitment survival on the population size fluctuations at these locations. In this study, recruitment is defined as the number of new recruits at the end of a discrete period of settlement. We hypothesise that the relative importance of the variation in different vital rates in shaping adult densities may differ between locations. That is, despite similar mean values of various vital rates, differences in their variation could produce dissimilar patterns in the small-scale population dynamics. For the same reason, populations may also show differences in their sensitivity to changes in life-cycle parameters. To test these hypotheses, we apply 2 stochastic matrix-based models, each incorporating a specific degree of variability in vital rates.

\section{MATERIALS AND METHODS}

Study organism and collection sites. The barnacle Semibalanus balanoides is a boreo-arctic species that is common in the intertidal on both sides of the north Atlantic and in the NE Pacific (see Barnes 1957a, 1958 
for details on distribution). S. balanoides is a crossfertilising hermaphrodite, and breeding occurs during late autumn or winter (Crisp \& Clegg 1960, Barnes 1963). The release of nauplii is induced by local environmental conditions (King et al. 1993) and generally occurs between March and May. S. balanoides has been extensively studied with regard to its regional and local distribution (Barnes 1957b, 1958, Kensler \& Crisp 1965, Kensler 1967), reproduction, embryo development and larval ecology (Barnes 1953, 1956, Crisp \& Clegg 1960, Barnes 1963, Barnes \& Barnes 1967, 1976, Arnold 1977, King et al. 1993) and settlement (e.g. Crisp \& Barnes 1954, Kendall et al. 1982, Jenkins et al. 2000). There is excellent information on distribution and zonation patterns (Barnes \& Powell 1950, Connell 1961, Barnes \& Barnes 1965, 1967, Minchinton \& Scheibling 1991) and also on the spatial and temporal differences in population vital rates (Kendall et al. 1982, Jenkins et al. 2000, 2001).

Extensive demographic data for Semibalanus balanoides were collected at 2 shores from each of 3 locations across Europe: the Isle of Man, SW Ireland and the west coast of Sweden. The names and positions of the shores can be found in Jenkins et al. (2001). In addition to being spatially separated, the locations differ in some abiotic aspects. The Isle of Man and SW Ireland have a regular tidal range of about 7 and $5 \mathrm{~m}$ respectively, and both locations have fully marine salinities (33 to $35 \mathrm{psu}$ ). In contrast, the west coast of Sweden has a small tidal range $(<0.3 \mathrm{~m})$, but irregular changes due to winds and atmospheric pressure differences produce water-level changes ranging from $0.5 \mathrm{~m}$ below to a maximum of $1.5 \mathrm{~m}$ above mean sea level. The west coast of Sweden also experiences large fluctuations in salinity (mean salinity $=24 \mathrm{psu}$ ), and ice cover occurs on average every fourth winter.

All shores at each location are semi-exposed and have abundant barnacle populations. Detailed physical and biological descriptions of the selected shores in the Isle of Man, SW Ireland and west Sweden can be found in Hartnoll \& Hawkins (1985), Power (2000) and Lindegarth et al. (2001) respectively.

Data collection. At each location, 2 randomly selected shores were sampled. On each shore 2 sites, at least $10 \mathrm{~m}$ apart, were chosen at random, and at each site 2 randomly located quadrats were sampled. Each quadrat was $5 \times 5 \mathrm{~cm}$ in size in SW Ireland and Isle of Man but $15 \times 15 \mathrm{~cm}$ in west Sweden. Barnacles are much larger in west Sweden, and larger quadrats were used in order to measure a comparable number of barnacles. Photographs were taken of each quadrat, using colour-reversal film, at the beginning and end of two 6 mo periods. New quadrats were selected at the beginning of the second period, producing different quadrats for the 2 time intervals. Shores in the Isle of
Man and SW Ireland were sampled for the periods June to December 1997 and December 1997 to June 1998, while west Sweden shores were sampled for the periods December 1996 to June 1997 and June to December 1997. The photographs were digitally analysed using Image Pro Plus (Media Cybernetics 1996). Every barnacle, between 50 and 400 individuals per square, was counted and measured for opercular, length at the start and end of each 6 mo period, producing measurements of growth, mortality and recruitment for each quadrat. Percentage cover of bare space was also recorded. For procedure standardisation, all photographs were analysed by the same operator.

Size categories. Barnacles are organisms of overlapping generations and varied growth, hence it can be difficult to separate individuals into different age classes (Jenkins et al. 2001). An alternative is to use size categories, which in the case of barnacles also correlate better with demographic rates and occupied space than does age. Hyder et al. (2001) found that in organisms in which growth rate decreases exponentially with size, the use of exponential size categories produces biologically valid size categories, for which the mean residence time in each size category is similar. Average size categories for Semibalanus balanoides were thus produced for each location by dividing into 3 equally large intervals the logarithm of the largest individual at each site; 3 size classes were necessary to adequately represent the size of juveniles and small adults (Class 1), intermediate-sized adults (Class 2) and large adults (Class 3).

Growth at the base of a barnacle may be affected by crowding (Stubbings 1975), and therefore opercular length of the barnacles was used as measure of size. However, since the amount of free space is determined by the area occupied by barnacles, 250, 143 and 96 randomly selected barnacles from the 3 locations were measured to calculate a mean conversion factor (C) between opercular length and barnacle radius. The average area $\left(m a_{i}\right)$ of an individual in a particular size category (i) could then be calculated. Knowing the number of individuals in each size category at time $t$ $\left(N_{i=1 \rightarrow 3, t}\right)$ and assuming that each individual in Size Category $i$ has an average size $m a_{i}$, the total occupied space $\left(a_{t}\right)$ by individuals of Semibalanus balanoides is calculated as the sum of space occupied by each size category.

Matrix models. We constructed 2 stochastic structured models to explain the density dynamics of an open population with space-limited recruitment. These were a periodic model with stochastic recruitment (Model 1) and a periodic model with stochastic survival and recruitment (Model 2). The mathematical theory behind matrix population models is extensive; for an introduction and general review see Caswell (2000), for 
extensive reviews see Cohen (1987), Tuljapurkar (1990) and Tuljapurkar \& Caswell (1997). Roughgarden et al. (1985) and Hyder et al. (2001) have previously employed similar, but deterministic structured models. The former authors constructed a theoretical model for a sessile organism with pelagic larvae, while the latter extended the theory and applied it to a particular species. The models used in this study are extensions of the model applications of Hyder et al. (2001).

Individuals in the barnacle populations were divided into the 3 separate size categories for each location. From these, 2 models were constructed using certain biologically derived assumptions. These were: (1) Semibalanus balanoides individuals could either survive in their current size category, increase in size to any of the next categories, or die; (2) populations were considered open and all new individuals recruited into the first size category; (3) mortality was size-specific (Jenkins et al. 2001) and independent of vital rates; (4) there was no spatial co-variation between mortality and recruitment; (5) recruitment was partly limited by space. Assumptions 3 to 5 were tested through statistical analyses.

In the model, the number of recruits was dependent on available free space $(F)$, which was incorporated into the recruitment process and defined as:

$$
F_{t}=A(1-O)-a_{t}
$$

where $A$ is total area, $a_{t}$ is the total space occupied by individuals of Semibalanus balanoides at time $t$, and $O$ is the mean proportion of occupied space per simulated area by other species. Apart from adult density, many other factors will have had a large impact on the number of recruits at different locations. A degree of stochastic variation was therefore incorporated into the recruitment process (see next subsection). Adding recruitment to the rest of the matrix model produces the following expressions of the number of individuals $\left(N_{s c, t}\right)$ in each size category $(S C)$ at time $t$ :

$$
\begin{gathered}
N_{1, t}=P_{11} N_{1, t-1}+F_{t-1} \times R_{t} \\
N_{2, t}=P_{21} N_{1, t-1}+P_{22} N_{2, t-1} \\
N_{3, t}=P_{31} N_{1, t-1}+P_{32} N_{2, t-1}+P_{33} N_{3, t-1}
\end{gathered}
$$

where $P_{i j}$ is the transition probability from Size Category $j$ to Size Category $i, F_{t-1}$ is available free space prior to recruitment, and $R_{t}$ is a randomly selected recruitment per area 'function' at time $t$.

Model simulations. The data sets of size-categorised individuals from the 8 quadrats from each 6 mo period were combined and used to produce 2 periodic transition matrices of size-specific growth and survival for each location. We derived 8 different recruitment state 'functions' from the winter-summer period for each location. This was done by simply dividing the measured total settlement at each site by the amount of free space before settlement. For a second stochastic model, 8 independent growth and survival matrices, to representing the existing environmental heterogeneity, were produced for each period and location.

To estimate the variation in demography caused by varied recruitment, the periodic model with stochastic density-dependent recruitment (Model 1) was used to simulate population density over time. In this model, the simulated time step equalled $1 \mathrm{yr}$ and was divided into 2 periods (summer-winter and winter-summer), each represented by an environmental state associated with a matrix describing the environment. This produced a periodic model with growth and survival rates alternating between spring and autumn. The recruitment was limited to the winter-summer period only. Data from 1997 were used for all populations, since recruitment in 1998 was unusually low in the Isle of Man (S. R. Jenkins pers. obs.). The recruitment procedure was a stochastic process. Every winter-summer period, it randomly extracted from the environment 1 of the 8 recruitment states derived from the data and its associated recruitment per area 'function', and multiplied this with available free space.

In Model 2, stochastic variation in individual growth and survival was introduced. For this procedure a finite-state ergodic Markov chain (Cohen 1987) was used to generate a sequence of environmental states and associated matrices, each randomly selected for the 2 periods out of the 16 independent environmental states derived from the data. This added a stochastic variation within each of the 2 periods resulting in $8 \times$ $8 \times 8(=512)$ possible combinations of annual periodic growth, survival and recruitment rates.

When running the 2 models, their respective generated sequence of projection matrices together with the recruitment process were applied to an initial population vector $N(0)$ to produce a sequence of population vectors - $(N(1), N(2), N(3) \ldots$ etc. $)$ - each representing the population state at a particular time. Assuming that the environment was homogenous and that the strong stochastic ergodic theorem was valid (Tuljapurkar 1982), the calculation of the average logarithmic population growth rate was then performed using the following 2 equations:

$$
\begin{gathered}
\ln \lambda_{i, s}=\ln \operatorname{sum}\left(N_{i+1}\right)-\ln \operatorname{sum}\left(N_{i}\right) \\
\ln \lambda_{s}=(1 /(T-1)) \sum_{i} \ln \lambda_{i, s}
\end{gathered}
$$

where $i$ represents each single time-step and $T$ is total simulated time $(i=1,2, \ldots, T)$ (Heyde \& Cohen 1985).

To avoid a change of scale, modelled scale is equivalent to sampled area. In Model 1, the total area (A) simulated was equivalent to the size of 8 sampled quadrats, $200 \mathrm{~cm}^{2}$ for the Isle of Man and SW Ireland and $1800 \mathrm{~cm}^{2}$ for west Sweden. Due to differences in model structure, the total area (A) simulated in Model 2 
was equivalent to the size of only 1 sampled quadrat, $25 \mathrm{~cm}^{2}$ for the Isle of Man and SW Ireland and $225 \mathrm{~cm}^{2}$ for west Sweden. Since each of these areas contains a number of individuals with varied life histories based on data from thousands of individuals, local population dynamics with regard to growth rate and free space can be taken as a good representation of the whole shore. The initial population size was set to zero for both models and a total of $10000 \mathrm{yr}$ were simulated. In the final analyses, the initial $100 \mathrm{yr}$ were disregarded to exclude any form of transient behaviour in demography and to allow the populations to reach their 'normal' population state. Important to note is that simulations for thousands of years are not predictions of future population size but only a method of examining the relative differences in spatial density dynamics at a stochastic steady state.

Average population growth rate $\left(\lambda_{s}\right)$, population size $(N)$, amount of free space $(F)$ and population structure $25 \mathrm{~cm}^{-2}$ and the simulated variation of these variables were calculated for Model 1 and Model 2 simulations. To compare the relative amounts of variation in populations with different means, variation values for population size $(N)$ and free space $(F)$ were converted into their coefficient of variation. Maximum population sizes and number of empty square events were also calculated.

Elasticity analysis. To further investigate the relative importance of recruitment and survival, an elasticity analysis was performed on Model 2. The aim of this analysis is to identify how much a population variable, such as population growth rate or free space, changes when 1 life-cycle stage is perturbed. Since the models developed are stochastic and density-dependent, an elasticity analysis of the population growth rate was not applicable. Similar to the model of Engel et al. (2001), an alternative variable (e.g. free space) was therefore used as the elasticity value. The procedure included making a small proportional change in a lifecycle stage (matrix element or recruitment state) and then measuring the proportional effects of such a change on the mean percentage of free space. The procedure was as follows: An element representing a particular survival or recruitment stage in the life-cycle was multiplied by a factor $(x)$ close to, but smaller than, unity. In the following model simulation, all elements other than those representing the life-cycle stage under investigation were left unchanged. A new mean percentage of free space was extracted from the simulations and the elasticity was calculated accordingly:

$$
S_{l s-i}=F_{a}-F_{o} /(1-X)
$$

where $\mathrm{S}_{l s-i}$ is the elasticity for life-cycle Stage $i_{1} F_{a}$ is the new simulated mean percentage of free space, $F_{o}$ is the original mean percentage of free space calculated from Model 2, and $(1-x)$ is a scaling factor correcting for the absolute size of factor $x$. Factor $x$ was initially set to 0.9 and then the process was repeated with factors closer to unity $(0.99,0.999, \ldots)$ until the elasticity value converged to a stable value. The same procedure was repeated for all stages in the life-cycle. An identical Markov chain was used in all simulations to elude differences in free space resulting from variation in the stochastic sample paths. Thus, 3 elasticity values for survival, 3 elasticity values for growth, and 1 mean elasticity value for recruitment could be extracted for each location.

\section{RESULTS}

\section{Assumption testing}

A regression analysis showed a significant relationship between the natural logarithm of barnacle opercular length and barnacle area $(\mathrm{p}<0.001)$, with high $\mathrm{R}^{2}$ values of $0.61,0.64$ and 0.86 for the Isle of Man, SW Ireland and west Sweden respectively. The conversion factors of opercular length to radius were $C=1.13$ for the Isle of Man, $C=1.19$ for SW Ireland and $C=1.34$ for west Sweden. Using these, the exponential sizecategories of opercular length were transformed into size-categories of area occupied (Table 1). Size categories differed substantially between the 3 locations. An average barnacle occupied a relatively small area in SW Ireland, a slightly larger area in the Isle of Man, and a very large area in west Sweden (Table 1).

Mortality was a significant decreasing function of available free space in west Sweden $\left(\mathrm{R}^{2}=0.33, \mathrm{p}<\right.$ 0.05), but not in the Isle of Man and SW Ireland. Mean mortality $( \pm \mathrm{SE})$ for each size category for all 3 locations is presented in Table 2. Compared to the transition matrices for the other 2 locations, the transition matrices

Table 1. Semibalanus balanoides. Exponential size categories for populations in Isle of Man, SW Ireland and west Sweden, expressed as space occupied by each size category. Values in parentheses: average area occupied by an average individual in a specific size category. Average size categoires calculated by dividing the logarithm of the larges individual at each site into equally large intervals. Size categories 1, 2, $3=$ juveniles and small adults intermediate-sized and large adults respectively

\begin{tabular}{|lccc|}
\hline $\begin{array}{l}\text { Size } \\
\text { category }\end{array}$ & Isle of Man & $\begin{array}{c}\text { Area }\left(\mathrm{mm}^{2}\right) \\
\text { SW Ireland }\end{array}$ & West Sweden \\
\hline 1 & $0-26.0$ & $0-11.8$ & $0-134.2$ \\
& $(6.8)$ & $(3.0)$ & $(33.7)$ \\
2 & $26.1-38.8$ & $11.9-20.0$ & $134.3-162.8$ \\
& $(32.6)$ & $(16.0)$ & $(149.0)$ \\
3 & $>38.8$ & $>20.0$ & $>162.8$ \\
& $(42.2)$ & $(23.3)$ & $(172.5)$ \\
\hline
\end{tabular}


for west Sweden generally had lower proportions of growth and survival (Table 3). In addition, west Sweden showed great differences between the first and second period. Survival and growth during Period 2 were much higher than during Period 1. Transition matrices for the Isle of Man and SW Ireland were quite similar (Table 3 ). The only marked difference was a very high proportion of growth from Size Categories 1 to 2 during Period 2 in SW Ireland.

Removing 1 extreme recruitment value at each location, recruitment was a significantly $(p<0.05)$ increasing function of free space at all locations. $\mathrm{R}^{2}$ values were $0.69,0.65$ and 0.84 for the Isle of Man, SW Ireland and west Sweden respectively. No significant spatial covariance was found between recruitment and juvenile mortality (correlation coefficients $=0.2575,0.2604$ and 0.1039 for the Isle of Man, SW Ireland and west Sweden respectively).

\section{Model simulations}

Stochastic growth rate. Model 1 simulations resulted in a stochastic steady state at all 3 locations, with average stochastic growth rates of 1.00. However, the variation in stochastic growth rate $V\left(\lambda_{s}\right)$ differed between locations (Table 4 ). There was relatively little variation in SW Ireland, intermediate variation in the Isle of Man, and high variation in west Sweden (Fig. 1, Table 4). The $V\left(\lambda_{s}\right)$ after recruitment was equivalent to the $V\left(\lambda_{s}\right)$ before recruitment.

Logically, Model 2 simulations also resulted in a stochastic steady state. The variation in stochastic growth rates was however higher at all locations. The difference in variation between models was relatively large in west Sweden, intermediate in SW Ireland, and low in the Isle of Man (Table 5, Fig. 1).

Table 2. Semibalanus balanoides. Mean $( \pm \mathrm{SE})$ mortality for each size category in Isle of Man, SW Ireland and west Sweden

\begin{tabular}{|lccc|}
\hline $\begin{array}{l}\text { Size } \\
\text { category }\end{array}$ & Isle of Man & $\begin{array}{c}\text { Mortality (\%) } \\
\text { SW Ireland }\end{array}$ & West Sweden \\
\hline 1 & $30.1( \pm 3.8)$ & $34.4( \pm 3.7)$ & $95.2( \pm 16.1)$ \\
2 & $25.1( \pm 6.8)$ & $19.0( \pm 2.2)$ & $84.6( \pm 5.3)$ \\
3 & $25.4( \pm 16.5)$ & $26.9( \pm 9.4)$ & $94.3( \pm 5.7)$ \\
\hline
\end{tabular}

Density and free space. The general density pattern over time among populations was the existence of several modal classes (Fig. 2). The Isle of Man population displayed a skewed density curve, with 3 to 4 defined peaks. The skewed density distribution produced large differences between the mean and the median population size: $\operatorname{mean}(N)-\operatorname{median}(N)=38$. The SW Ireland population on the other hand varied greatly in density and only showed faint aggregations around 3 different densities. The density in the west Swedish

Table 4. Semibalanus balanoides. Results from Model 1 runs of 3 barnacle populations, showing variation in population growth rate $(V[\lambda])$, mean population size $(N)$, average percentage free space $(F) 25 \mathrm{~cm}^{-2}$ and their corresponding coefficients of variation (CV) before and after recruitment $(R)$, in Isle of Man, SW Ireland and west Sweden

\begin{tabular}{|lrrrrr|}
\hline Population & $V(\lambda)$ & $N$ & $\mathrm{CV}(N)$ & $F(\%)$ & $\mathrm{CV}(F)$ \\
\hline $\begin{array}{l}\text { Isle of Man } \\
\text { before } R\end{array}$ & 0.30 & 171 & 48.6 & 41.5 & 46.3 \\
$\quad$ after $R$ & 0.30 & 282 & 48.7 & 18.8 & 92.4 \\
$\begin{array}{l}\text { SW Ireland } \\
\quad \text { before } R\end{array}$ & 0.08 & 190 & 20.5 & 35.0 & 21.3 \\
$\quad$ after $R$ & 0.09 & 283 & 22.1 & 21.8 & 40.5 \\
$\begin{array}{l}\text { West Sweden } \\
\text { before } R\end{array}$ & 0.63 & 6 & 68.2 & 86.6 & 9.5 \\
$\quad$ after $R$ & 0.55 & 90 & 62.8 & 11.6 & 111.5 \\
\hline
\end{tabular}


population was predominantly low, with sporadic shifts to higher densities.

In Model 1 simulations, the Isle of Man and SW Ireland had similar high mean densities of barnacles and intermediate percentages of available free space (Table 4). In comparison, west Sweden had a much lower mean population size, in particular before recruitment, with a corresponding high percentage of available free space (Table 4). West Sweden displayed large differences in free space between 'before' and 'after' recruitment, which indicated high mortality rates of recruits and rapid turnover of space. Consequently, the small population in west Sweden had a higher proportional variation in population size $\mathrm{CV}(N)$ than did the much larger populations in the Isle of Man and SW Ireland (Table 4). However, model simulations showed that barnacle populations in the Isle of Man and SW Ireland generally had higher coefficients of variation for available free space $C V(F)$ than west Sweden, at least before recruitment. The Isle of Man experienced the largest fluctuations in the proportion of available free space (Table 4).

In Model 2 simulations, mean densities and free space were similar to Model 1 simulations (Tables 4 \&

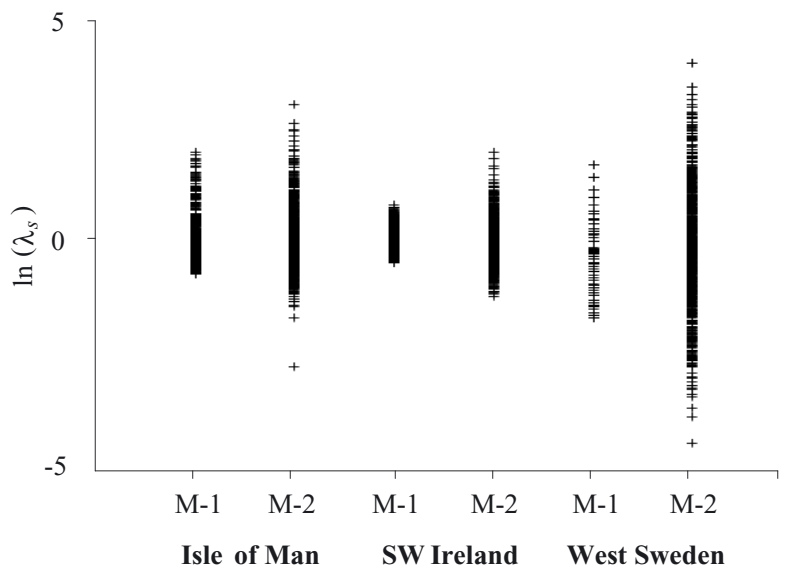

Fig. 1. Semibalanus balanoides. Range of stochastic growth rate $\left(\lambda_{s}\right)$ for Model $1(\mathrm{M}-1)$ and Model $2(\mathrm{M}-2)$ runs of populations in Isle of Man, SW Ireland and west Sweden

5). However, the variation for population size and percentage of free space was generally higher. The proportional increase of this variation was similar and quite large for SW Ireland and west Sweden (Tables 4 \& 5). Conversely, the variation in density and free
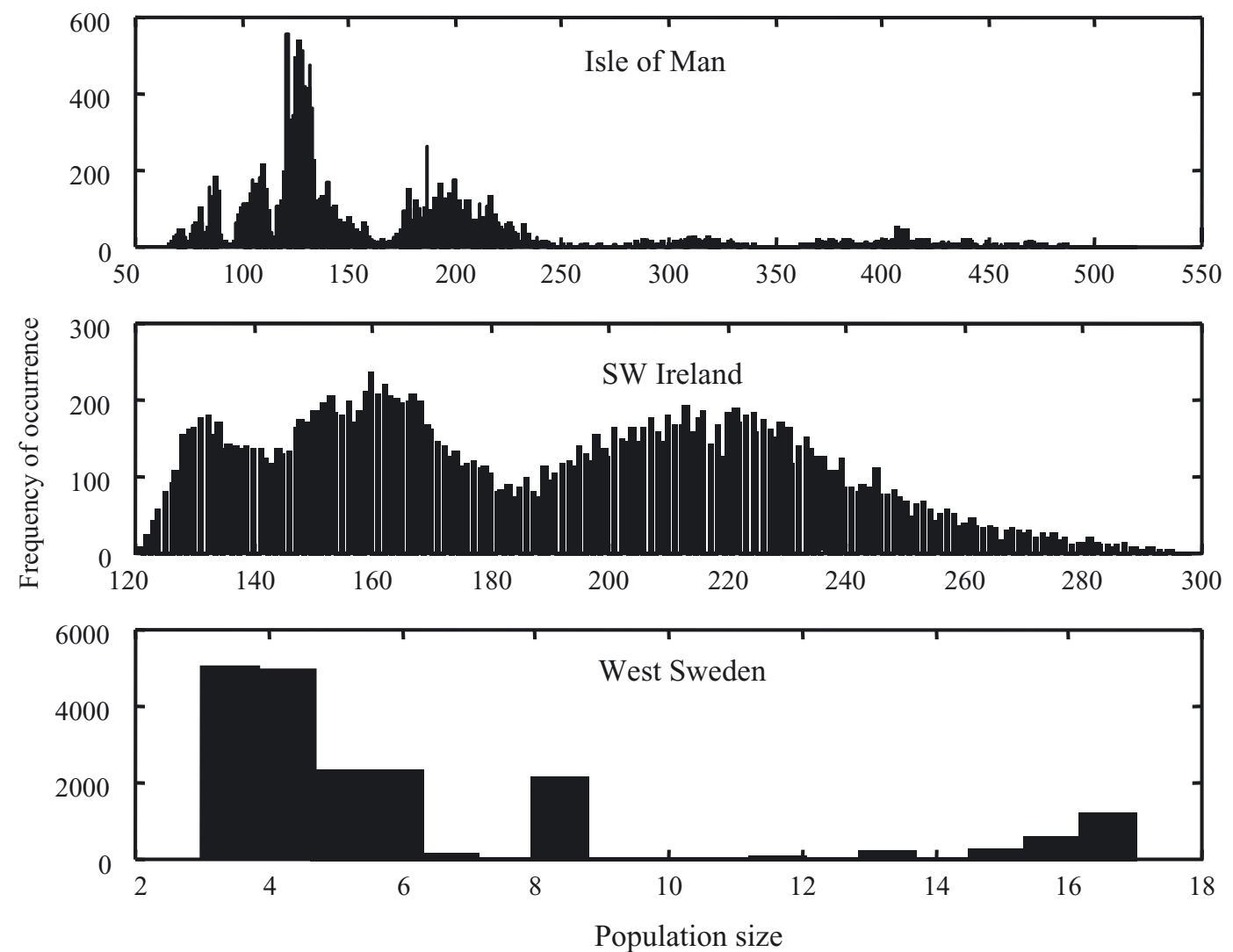

Fig. 2. Semibalanus balanoides. Frequency histograms of population size $(N)$ after Period 1 (before recruitment) simulated for the period of $20000 \mathrm{yr}$ for Isle of Man, SW Ireland and west Sweden. Each bin represents an integer number of individuals $25 \mathrm{~cm}^{-2}$ 


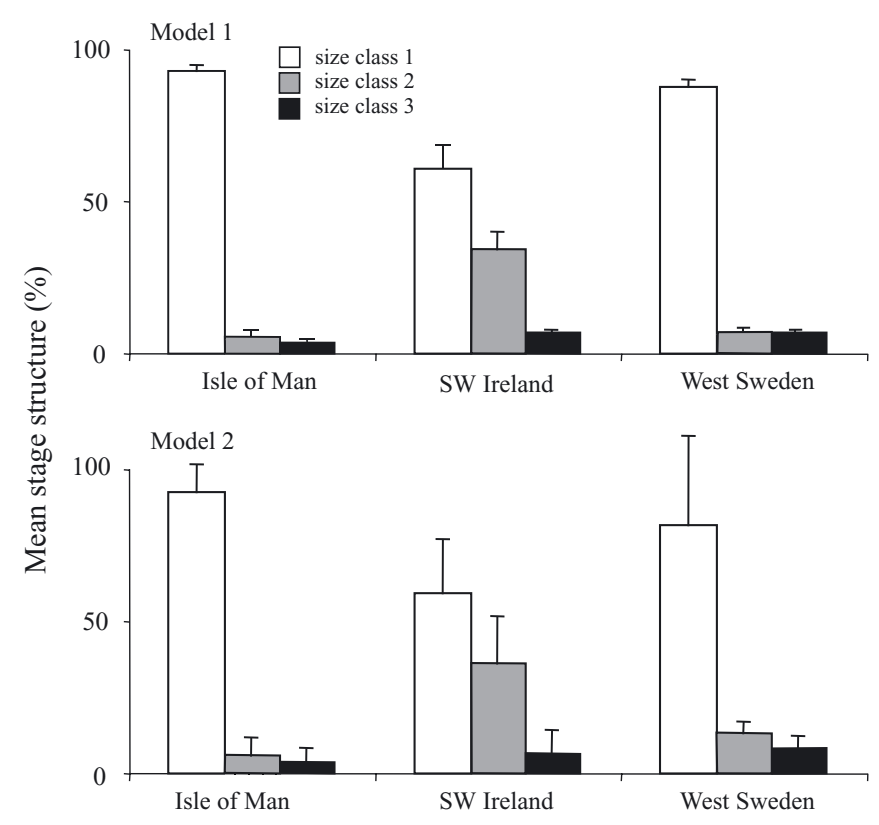

Fig. 3. Semibalanus balanoides. Model 1 and Model 2 simulated mean percentage $( \pm \mathrm{SD})$ of individuals in each size category after Period 1 (before recruitment) for populations in Isle of Man SW Ireland and west Sweden respectively

Table 5. Semibalanus balanoides. Results from Model 2 runs of 3 barnacle populations, showing mean population growth rate $(\lambda)$ and its variation $(V)$ and mean population size $(N)$ and average percentage of free space $(F) 25 \mathrm{~cm}^{-2}$ and their corresponding coefficients of variation (CV) before and after recruitment $(R)$, in Isle of Man, SW Ireland and west Sweden

\begin{tabular}{|lrrrrr|}
\hline Population & $V(\lambda)$ & $N$ & $\mathrm{CV}(N)$ & $F(\%)$ & $\mathrm{CV}(F)$ \\
\hline $\begin{array}{l}\text { Isle of Man } \\
\quad \text { before } R\end{array}$ & 0.46 & 167 & 60.5 & 44.6 & 53.0 \\
$\quad$ after $R$ & 0.37 & 280 & 56.5 & 21.8 & 96.4 \\
$\begin{array}{l}\text { SW Ireland } \\
\quad \text { before } R\end{array}$ & 0.25 & 190 & 35.4 & 35.8 & 55.3 \\
$\quad$ after $R$ & 0.22 & 283 & 35.2 & 25.2 & 74.7 \\
$\begin{array}{l}\text { West Sweden } \\
\text { before } R\end{array}$ & 2.21 & 6 & 130.4 & 87.6 & 29.6 \\
$\quad$ after $R$ & 0.57 & 86 & 64.9 & 13.0 & 105.8 \\
\hline
\end{tabular}

Table 6. Number of empty-square events and maximum population size (max. N) $25 \mathrm{~cm}^{-2}$ for Model 1 and Model 2 runs at the same scale

\begin{tabular}{|lcccc|}
\hline Population & \multicolumn{2}{c}{$\begin{array}{c}\text { No. of empty-square } \\
\text { events }\end{array}$} & \multicolumn{2}{c|}{ Max. N } \\
& Model 1 & Model 2 & Model 1 & Model 2 \\
\hline Isle of Man & 0 & 0 & 507 & 766 \\
SW Ireland & 0 & 0 & 289 & 423 \\
West Sweden & 0 & 124 & 11 & 37 \\
\hline
\end{tabular}

space had increased relatively little in the Isle of Man. The added stochasticity in survival also resulted in more frequent empty-square events in west Sweden and an amplification of the maximum population sizes at all locations (Table 6).

Structure. In Model 1 simulations, the Isle of Man and west Sweden were mainly comprised of individuals of Size Category 1, while comparatively few individuals were of Size Category 2 or 3 (Fig. 3). SW Ireland, however, had an almost linear negative relationship between size category and its corresponding proportion of individuals. The standard deviations were consistently low for each size category across locations, indicating relatively stable population structures in all 3 populations (Fig. 3).

Adding stochastic growth and survival (Model 2) did not alter the size distribution of individuals at any of the 3 locations (Fig. 3). However, across locations there was an increase of the standard deviation for each size category.

Elasticity. At all locations, free space was most sensitive to changes in survival within a size class (Fig. 4). In the Isle of Man and west Sweden, changes in survival for Size Category 1 had the largest effect on free space. In SW Ireland, free space was most sensitive to changes in survival within Size Category 2. Furthermore, in the Isle of Man and SW Ireland, free space was more sensitive to changes in growth than in recruitment. West Sweden showed similar elasticities for growth (Elements 2,1; 3,2; and 3,1) and recruitment $(R)$.

\section{DISCUSSION}

This study found that a data-based model of an open population with space-limited recruitment is a good representation of real population dynamics of the barnacle Semibalanus balanoides. Through simulations of population size and free space, it was discovered that different life-cycle factors have a varied influence on the population dynamics at spatially separated locations. Primarily, it was the relative importance of recruitment and survival in shaping adult density that differed substantially between locations. The magnitude of the local variation in these vital rates was shown to be responsible for the fluctuations in population density and structure. Furthermore, the elasticity analysis indicated that free space is generally more sensitive to changes in growth/survival than changes in recruitment. It was also confirmed that locations with already high variability in vital rates were less sensitive to disturbances. These findings and the supporting evidence are discussed below. 


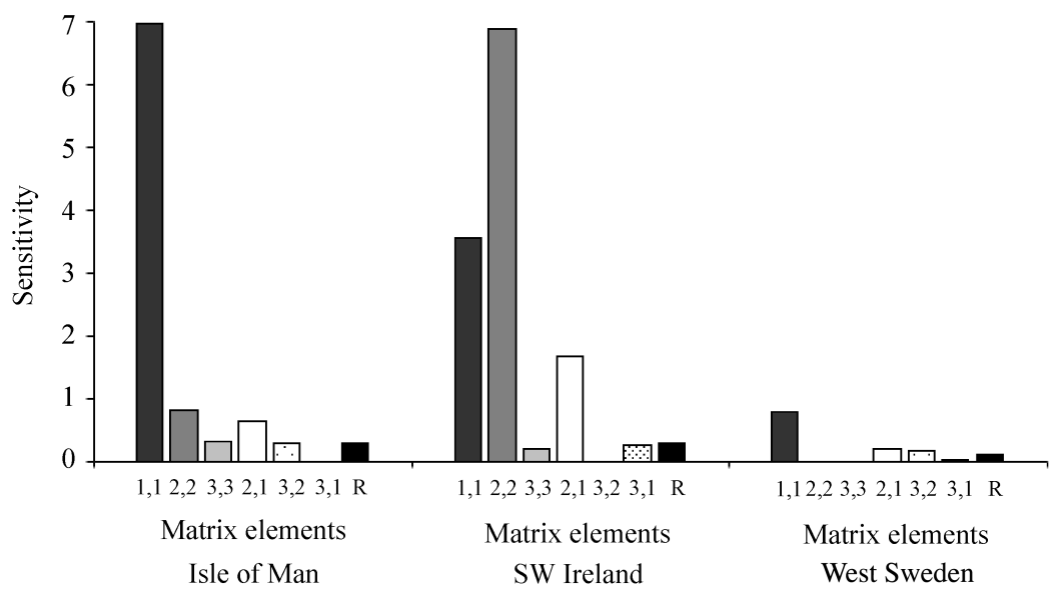

Fig. 4. Semibalanus balanoides. Sensitivity of free space to changes in survival (Matrix element 1,$1 ; 2,2 ; 3,3$ ), growth (Matrix element 2,$1 ; 3,2 ; 3,1$ ) and recruitment $(R)$, for populations in Isle of Man, SW Ireland and west Sweden

the total area after recruitment. For this population it could be argued that a density-dependent mortality function should be included in the model, similar to that used by Roughgarden et al. (1985). However, possible effects of high densities on mortality seemed to already be included in the stage-specific growth and survival functions for west Sweden. Juvenile mortality early after recruitment increased mean available free space from 11 to $86 \%$ of total area during Period 2. To facilitate comparison of results between locations, density-dependent mortality was not incorporated into the model.

Mortality was size-specific at all locations, demonstrating that different sizecategories for each location were required to produce realistic projections of mortality and survival. An unexpected result

\section{Assumption testing and model validity}

Jenkins et al. (2001) showed that there were great differences in size between barnacles from the Isle of Man and SW Ireland and barnacles in west Sweden, with those from the most southerly locations being smallest. Size categories in this study therefore differed substantially between locations. Caswell (2000) and Hyder et al. (2001) discussed the difficulties in comparing simulated population dynamics for populations of different size categories, since the stage-specific survival in different populations would be based on dissimilar assumptions. However, an important reason for applying structured models is to find differences in population dynamics resulting from heterogeneity in population parameters (Caswell et al. 1997). Since individual size for barnacles is, to a certain degree, coupled with age, large dissimilarities in growth would confound the age distribution in the different populations. Furthermore, the longevity of Semibalanus balanoides varies with level on the shore and in relation to position within the geographical range of the species (Stubbings 1975). Therefore, if collected data indicate large differences in size or individual growth rate between populations, such as in this study, environmental standardisation might not effectively reflect reality and different size categories should be used.

In the model it was assumed that mortality was independent of all other vital rates. This was not a valid assumption for the west Swedish population. Gaines \& Roughgarden (1985) suggest that density-dependent mortality becomes important when available free space drops below $15 \%$ of the total area, and in west Sweden the average free space was only 11 to $13 \%$ of was that mortality was higher for large individuals than for smaller ones in west Sweden. The data also revealed the expected pattern that small and old large individuals are likely to experience higher mortality, since they are expected to be more sensitive to stressful environmental conditions, such as desiccation and mechanical disturbances (Barnes \& Powell 1950).

Extreme recruitment values had to be removed for available free space to significantly explain the majority of the variation in recruitment. However, spacelimited recruitment has been shown to be a valid assumption for other barnacle populations (Roughgarden 1971, Roughgarden et al. 1985, Hyder et al. 2001). Nonetheless, settlement and recruitment depend also on other factors (see 'Introduction') and the degree of density-dependence is likely to vary between and within locations (Caley et al. 1996) and with scale (Wiens 1989). This stresses the need for caution when using strict density-dependence in population models, and motivates the use of an approach with varying recruitment.

Obviously spatial variation measured during 1 year cannot be regarded as a valid representation of temporal variability. For example, it is known that the Isle of Man can experience occasional years of very low recruitment (Jenkins et al. 2000). Also, SW Ireland may experience exceptionally stormy weather and west Sweden years with ice (Åberg 1992), which may severely affect barnacle survival in these areas. These are all factors that produce variation in population dynamics. However, based on what is known about these shores and comparisons with earlier studies, the data used in this study represent the general demography of these shores fairly well. Hence, model simulations and predictions are reasonably realistic. 


\section{Population dynamics}

In a model where 1 or several traits are directly or indirectly dependent on population density, stochastic or not, there is a limit to the number of recruits per area, and thus a limit to the number of individuals entering and occupying an area. This creates an upper limit for the simulated population size. Also, in an open population with asynchronous local population dynamics, there always exists the possibility of new settlement by larvae entering from adjacent populations, which will promote recolonisation after extinction of a local population (Roughgarden et al. 1985). Together these factors will produce an average stochastic growth rate of 1 for any population if the model runs long enough. This type of open-population model can be seen as a spatially implicit mainland-island metapopulation model (defined as in Hanski \& Simberloff 1996), whereby a mainland population, represented by the summed surrounding populations, continuously supplies the local (island) population with new individuals. Consequently, the model structure itself may create a general stability for the studied population and, from theory, it is not clear how such a model should be properly analysed (Caswell 2000).

The model application in this study supported the theory that increased stochasticity (Model 2) should result in increased variation in population size, structure and free space (Caswell 2000). This was mainly a result of occasional combinations of extremes in recruitment and survival functions, which intensified the fluctuations in population dynamics. A general explanation for this trend in modelled population dynamics is that these are open-population models, in which recruitment is not coupled to fecundity of the local population. This is not an entirely correct description of known natural processes, because large-scale environmental conditions are likely to affect both sources and sinks (Levin \& Pacala 1997). Also, there is no real temporal variation included in the model. Constructing a spatially structured model (Gyllenberg et al. 1996) of this species with dispersal probabilities as functions of distance and local and global hydrodynamics may produce a situation where the variation in recruitment compensates for the variation in survival, resulting in increased stability in population dynamics when more demographic stochasticity is added. To date, not enough data exist to support the construction of such a model for Semibalanus balanoides.

The model runs produced average population sizes that were coherent with earlier observations of these populations (Jenkins et al. 2001). Comparison of the results of Model Simulations 1 and 2, whereby Model 2 included more variation than Model 1, indicates that both variability in survival and growth and variability in recruitment induced variability in the population growth rate in west Sweden. Thus, both these vital rates seem to be important factors in shaping adult densities at this location. From Model 1 simulations, it was obvious that SW Ireland had the lowest variation in population growth rate. As anticipated from Jenkins et al. (2000), this confirmed that variability in recruitment was fairly low. The substantially higher variation displayed in Model 2 runs then revealed that variability in survival and growth generated the most variability in the population growth rate. In the Isle of Man, the variability in population growth rate was similar in Model 1 and Model 2 simulations. This indicates that recruitment had the greatest impact on population growth rate in the Isle of Man. Hence, the Isle of Man and SW Ireland, which otherwise had similar mean values of many population variables (Jenkins et al. 2000, 2001), displayed great dissimilarities in the relative importance of recruitment and survival shaping the adult population.

The coefficient of variation for free space before recruitment was generally lower for the low-density population in west Sweden than for the larger populations in the Isle of Man and SW Ireland. Logically, the corresponding coefficient of variation for population size showed the reverse pattern. However, aside from Sweden separating itself from the other 2 locations, there was also a clear difference in variation in both free space and population size between the Isle of Man and SW Ireland. Such difference cannot be explained by the relative size of each population, since these locations have barnacle populations of similar sizes. The only plausible explanation is that differences in the variability of growth/survival and recruitment generate dissimilar fluctuations in population variables.

General density dynamics and population structure were also quite specific for each population. In the Isle of Man and west Sweden, the populations had a few common and widely separated modal classes and consisted almost entirely of small individuals. In SW Ireland, however, the population had less distinct modal classes and a more linear relationship between size and abundance. The population dynamics and structure at each location may explain part of this pattern. In both the Isle of Man and west Sweden, variation in recruitment was great and the populations consisted mainly of Size Class 1 individuals. Peaks and lows in recruitment were, therefore, to a certain degree creating boundaries for the shape of the adult population. Population turnover was probably also faster. In SW Ireland, however, variation in recruitment was low and the population had higher proportions of larger individuals. Therefore, the varied growth and survival had a large impact on population dynamics, resulting in a wider density spectrum of returning adults. 
It is important to note that these simulated dynamics are also the consequence of biological interactions among species (Underwood 2000). These interactions are not explicitly included in the model, but a certain degree of such effects are hidden within the recruitment and survival functions. Therefore, modelling studies of single-species dynamics, such as this one, present a possible description of the larger community (Tilman et al. 1997). For instance, large fluctuations in population size could be a result of not only environmental variability but also intense biological interactions. The role of key consumers and space occupiers in the structuring mid-shore community of moderately exposed shores in the NE Atlantic are well characterised (see Hawkins et al. 1992 for review). If model results from studies such as ours can be coupled with such known interactions at a particular location, the modelled variation in population size of a species could also provide a measurement of the effects of biological interactions.

\section{Elasticity}

Although there is much confusion about the power of sensitivity analyses (for a review see de Kroon et al. 2000), the results strongly suggest that free space is generally more sensitive to changes in survival than in recruitment. Hence, at this stage, population density is largely restricted by the capacity of adult individuals to cope with local environmental and biological stress. Also, and equally as important, our results indicate that populations with already high variability in vital rates are better able to buffer further changes. Thus, the more unstable population in west Sweden had low sensitivity values, the population in the Isle of Man higher, and the population in SW Ireland the highest. This capability of a population to make changes in vital rates could potentially be important in areas with much anthropogenic activity or areas that undergo changes in climate.

\section{CONCLUSION}

The assumption testing and model simulations supported the use of an open population model with spacelimited recruitment to simulate population dynamics of the barnacle species Semibalanus balanoides. Simulations of population size and free space for $S$. balanoides were relatively persistent across Europe and consistent with earlier results (Jenkins et al. 2000, 2001). As expected from theory, added stochasticity in demographic rates (Model 2) generated more variation in population dynamics for all populations, especially in SW Ireland and west Sweden. Simulations also indicated that the relative importance of recruitment and survival in shaping adult density much depend on the existing variation in these vital rates at each location. Furthermore, the relative variation in different vital rates seems to strongly affect the population density dynamics and structure. Generally, free space seemed more sensitive to changes in growth/survival than changes in recruitment, suggesting that at this stage growth/ survival and not recruitment are the main factors in shaping adult densities at these locations. Furthermore, the elasticity analysis confirmed that locations with already high variability in vital rates were more buffered to overall changes in recruitment and survival. These patterns show that even within species, different lifecycle factors may influence the population dynamics at different locations. This could in turn indicate a difference in selection pressure between widely separated populations. However, most of these results are probably better explained by differences in environmental conditions and biological interactions between locations. Further work to elucidate the demography of $S$. balanoides should address large-scale genetic structure and the construction of a spatially explicit model of a subdivided population, with migration parameters included. Such a model requires accurate recruitment and dispersal estimates (Todd 1998), which would have to be attained through combined studies of the local hydrography, multi-scale genetics and larval behaviour of this species.

Acknowledgements. This study was performed as a part of the project EUMAR (EU EVK3-CT-2001-00048). Data were obtained from EUROROCK (EU MAS3-CT95-0012), and we thank our colleagues in the British Isles, Ireland and Sweden for collecting field data. Furthermore, we would like to thank Kieran Hyder for making valuable comments on the manuscript.

\section{LITERATURE CITED}

Åberg P (1992) A demographic study of two populations of the seaweed Ascophyllum nodusum. Ecology 73:1473-1487

Arnold DC (1977) Fecundity of Balanus balanoides in Passamaquoddy bay. J Fish Board Can 34:273-275

Barnes H (1953) The effect of lowered salinity on some barnacle nauplii. J Anim Ecol 22:328-330

Barnes H (1956) Balanus balanoides (L.) in the Firth of Clyde: the development and annual variation of the larval population, and the causative factors. J Anim Ecol 25:72-84

Barnes H (1957a) The northern limits of Balanus balanoides (L.). Oikos 8:1-15

Barnes H (1957b) Processes of restoration and synchronisation in marine ecology: the spring diatom outburst and the 'spawning' of the common barnacle Balanus balanoides (L.). Annee Biol 33:67-85

Barnes H (1958) The southern limits of Balanus balanoides (L.). Oikos 9:139-157 
Barnes H (1963) Light, temperature and the breeding of Balanus balanoides. J Mar Biol Assoc UK 43:213-223

Barnes H, Barnes M (1965) Egg size, nauplius size, and their variation with local, geographical, and specific factors in some common cirripedes. J Anim Ecol 34:391-402

Barnes H, Barnes M (1967) The effect of starvation and feeding on the time of production of egg masses in the boreoarctic cirripede Balanus balanoides (L.). J Exp Mar Biol Ecol 1:1-6

Barnes H, Barnes M (1976) The rate of development of the embryos of Balanus balanoides from a number of European and American populations, and the designation of local races. J Exp Mar Biol Ecol 24:251-269

Barnes H, Powell HT (1950) The development, general morphology and subsequent elimination of barnacle populations, Balanus crenatus and B. balanoides, after a heavy initial settlement. J Anim Ecol 19:175-179

Bertness MD, Gaines SD, Bermudez D, Sanford E (1991) Extreme spatial variation in the growth and reproductive output of the acorn barnacle Semibalanus balanoides. Mar Ecol Prog Ser 75:91-100

Caley MJ, Hughes TP, Jones GP, Carr MH, Hixon MA, Menge BA (1996) Recruitment and the local dynamics of open marine populations. Annu Rev Ecol Syst 27:477-500

Caswell H (2000) Matrix population models, Vol 2. Sinauer Associates, Sunderland, MA

Caswell H, Nisbet RM, de Roos AM, Tuljapurkar SD (1997) Structured population models: many methods, a few basic concepts. In: Tuljapurkar SD, Caswell H (eds) Structured population models in marine, terrestrial and freshwater systems. Chapman \& Hall, New York, p 3-17

Cohen JE (1987) Stochastic demography. In: Kotz S, Johnson NL (eds) Encyclopedia of statistical sciences, Vol 8. John Wiley, New York, p 789-801

Connell JH (1961) Effects of competition, predation by Thais lapillus, and other factors on natural populations of the barnacle, Balanus balanoides (L.). Ecol Monogr 31:61-104

Connell JH (1985) The consequences of variation in initial settlement vs post-settlement mortality in rocky intertidal communities. J Exp Mar Biol Ecol 93:11-45

Crisp DJ, Barnes H (1954) The orientation and distribution of barnacles at settlement with particular reference to surface contour. J Anim Ecol 23:142-162

Crisp DJ, Clegg DJ (1960) The induction of the breeding condition in Balanus balanoides (L.). Oikos 11:265-276

Dayton PK (1971) Competition, disturbance, and community organisation: the provision and subsequent utilisation of space in a rocky intertidal community. Ecol Monogr 41: 351-389

de Kroon H, van Groenendael J, Ehrlen J (2000) Elasticities: a review of methods and model limitations. Ecology 81: 607-618

Doherty PJ (1981) Coral reef fishes: recruitment limited assemblages? Proc 4th Int Coral Reef Symp, Manila 2:465-470

Engel C, Åberg P, Gaggiotti O, Destombe C, Valero M (2001) Population dynamics and stage structure in a haploiddiploid red seaweed, Gracilaria gracilis. J Ecol 89:436-450

Fraschetti S, Giangrande A, Terlizzi A, Boero F (2002) Preand post-settlement events in benthic community dynamics. Oceanol Acta 25:285-295

Gaines SD, Roughgarden J (1985) Larval settlement as a leading determinant of structure in an ecological community of the rocky intertidal. Proc Natl Acad Sci USA 82:3707-3711

Grosberg RK, Levitan DR (1992) For adults only — supply-side ecology and the history of larval biology. Trends Ecol Evol $7: 130-133$
Gyllenberg M, Hanski IA, Hastings A (1996) Structured metapopulation models. In: Hanski IA, Gilpin ME (eds) Metapopulation biology. Academic Press, San Diego, p 93-122

Hanski IA (1996) Metapopulation dynamics: from concepts and observations to predictive models. In: Hanski IA, Gilpin ME (eds) Metapopulation biology. Academic Press, San Diego, p 69-91

Hanski IA, Simberloff D (1996) The metapopulation approach, its history, conceptual domain, and application to conservation. In: Hanski IA, Gilpin ME (eds) Metapopulation biology. Academic Press, San Diego, p 5-26

Hartnoll RG, Hawkins SJ (1985) Patchiness and fluctuations on moderately exposed shores. Ophelia 24:53-64

Hawkins SJ (1983) Interactions of Patella and macroalgae with settling Semibalanus balanoides. J Exp Mar Biol Ecol 71:55-72

Hawkins SJ, Hartnoll RG (1982) Settlement patterns of Balanus balanoides (L.) in the Isle of Man (1977-1981). J Exp Mar Biol Ecol 62:271-283

Hawkins SJ, Hartnoll RG, Kain JM, Norton TA (1992) Plant-animal interactions on hard substrata in the northeast Atlantic. In: John DM, Hawkins SJ, Price JH (eds) Plant-animal interactions in the marine benthos. Systematics Association Special Volume No 46. Clarendon Press, Oxford, p 1-32

Heyde CC, Cohen JE (1985) Confidence intervals for demographic projections based on products of random matrices. Theor Popul Biol 27:120-153

Hills JM, Thomason JC, Milligan JL, Richardson M (1998) Do barnacle larvae respond to multiple settlement cues over a range of spatial scales. Hydrobiologia 375/376:101-111

Holmes SP (2002) The effect of pedal mucus on barnacle cyprid settlement: a source for indirect interactions in the rocky intertidal. J Mar Biol Assoc UK 82:117-129

Hughes TP, Baird AH, Dinsdale EA, Moltschaniwskyj NA, Pratchett MS, Tanner JE, Willis BL (2000) Supply-side ecology works both ways: the link between benthic adults, fecundity, and larval recruits. Ecology 81:2241-2249

Hyder K, Åberg P, Johnson MP, Hawkins SJ (2001) Models of open populations with space limited recruitment: extension of theory and application to the barnacle Chthamalus montagui. J Anim Ecol 70:853-863

Jeffery CJ (2000) Settlement in different-sized patches by the gregarious intertidal barnacle Chamaesipho tasmanica Foster and Anderson in New South Wales. J Exp Mar Biol Ecol 252:15-26

Jenkins RR, Åberg P, Cervin G, Coleman RA and 9 others (2000) Spatial and temporal variation in settlement and recruitment of the intertidal barnacle Semibalanus balanoides (L.) (Crustacea: Cirripedia) over a European scale. J Exp Mar Biol Ecol 243:209-225

Jenkins RR, Åberg P, Cervin G, Coleman RA and 8 others (2001) Population dynamics of the intertidal barnacle Semibalanus balanoides at three European locations: spatial scales of variability. Mar Ecol Prog Ser 217:207-217

Kendall ME, Bowman RS, Williamson P, Lewis JR (1982) Settlement patterns, density and stability in the barnacle Balanus balanoides. Neth J Sea Res 16:119-126

Kensler CB (1967) Desiccation resistance of intertidal crevice species as a factor in their zonation. J Anim Ecol 36:391-406

Kensler CB, Crisp DJ (1965) The colonisation of artificial crevices by marine invertebrates. J Anim Ecol 34:507-516

King PA, McGrath D, Morgan R, Fitzgerald O, Mullins P, Raleigh J (1993) Reproduction and settlement of the barnacle Semibalanus balanoides (L.) in Galway Bay. Proc R Irish Acad Sect B Geol Chem Sci 93B:5-12 
Knight-Jones EW (1953) Laboratory experiments on gregariousness during settling in Balanus balanoides and other barnacles. J Exp Biol 30:584-598

Levin SA (1992) The problem of pattern and scale in ecology; the Robert H. MacArthur award lecture. Ecology 73: 1943-1967

Levin SA, Pacala SW (1997) Theories of simplification and scaling of spatially distributed processes. In: Tilman D, Kareiva P (eds) Spatial ecology. Princeton University Press, Princeton, NJ, p 271-296

Lindegarth M, Åberg P, Cervin G, Nilsson P (2001) Effects of grazing on the structure of mid-shore, intertidal assemblages on moderately exposed rocky shores of the Swedish west coast. Mar Ecol Prog Ser 212:29-38

Menge BA (2000) Recruitment vs postrecruitment processes as determinants of barnacle population abundance. Ecol Monogr 70:265-288

Minchinton TE, Scheibling RE (1991) The influence of larval supply and settlement on the population structure of barnacles. Ecology 72:1867-1879

Nisbet RM, Gurney WSC (1982) Modelling fluctuating populations, Vol 1. John Wiley \& Sons, New York

Olivier F, Tremblay R, Bourget E, Rittschof D (2000) Barnacle settlement: field experiments on the influence of larval supply, tidal level, biofilm quality and age on Balanus amphitrite cyprids. Mar Ecol Prog Ser 199:185-204

Pineda J, Caswell H (1997) Dependence of settlement rate on suitable substrate area. Mar Biol 129:541-548

Power AM (2000) The ecology of chthamalid barnacles, an evaluation of settlement and recruitment in regulating the intertidal distribution of Chthamalus stellatus and C. montagui in south-west Ireland. PhD thesis, National University of Ireland, Cork

Raimondi PT (1990) Patterns, mechanisms, consequences of variability in settlement and recruitment of an intertidal barnacle. Ecol Monogr 60:283-309

Roughgarden J (1971) Density-dependent natural selection. Ecology 52:453-468

Editorial responsibility: Roger Hughes (Contributing Editor), Bangor, UK
Roughgarden J, Iwasa Y, Baxter C (1985) Demographic theory for an open marine population with space-limited recruitment. Ecology 66:54-67

Stubbings HG (1975) Balanus balanoides. LMBC Memoirs No. 31, Liverpool University Press, Liverpool

Thorson G (1950) Reproduction and larval ecology of marine bottom invertebrates. Biol Rev 25:1-45

Tilman D, Lehman CL, Kareiva P (1997) Population dynamics in spatial habitats. In: Tilman D, Kareiva P (eds) Spatial ecology. Princeton University Press, Princeton, NJ, p 3-20

Todd CD (1998) Larval supply and recruitment of benthic invertebrates: do larvae always disperse as much as we believe. Hydrobiologia 375/376:1-21

Tuljapurkar SD (1982) Population dynamics in variable environments. II. Correlated environments, sensitivity analysis and dynamics. Theor Popul Biol 21:114-140

Tuljapurkar SD (1990) Population dynamics in variable environments, Vol 1. Springer-Verlag, New York

Tuljapurkar SD (1997) Stochastic matrix models. In: Tuljapurkar SD, Caswell H (eds) Structured-population models in marine, terrestrial, and freshwater systems. Chapman \& Hall, New York, p 59-88

Tuljapurkar SD, Caswell H (1997) Structured population models in marine, terrestrial and freshwater systems, Vol 1. Chapman \& Hall, New York

Underwood AJ (2000) Experimental ecology of rocky intertidal habitats: what are we learning? J Exp Mar Biol Ecol 250:51-76

Vandermeer J (1978) Choosing category size in a stage projection matrix. Oecologia 32:79-74

Wieczorek SK, Todd CD (1998) Inhibition and facilitation of settlement of epifaunal marine invertebrate larvae by microbial biofilm cues. Biofouling 12:81-118

Wiens JA (1989) Spatial scaling in ecology. Funct Ecol 3: 385-397

Young CM, Gotelli NJ (1988) Larval predation by barnacles: effects on patch colonisation in a shallow subtidal community. Ecology 69:624-634

Submitted: October 21, 2003; Accepted: February 25, 2004 Proofs received from author(s): June 23, 2004 